\title{
Cefaleia: migrânea e qualidade de vida
}

\author{
Headache: migraine and quality of life \\ Nathalye Emanuelle Souza ${ }^{3}$, Mariana Leão Calumby ${ }^{1}$, Elisangela de Oliveira Afonso ${ }^{1}$, Thiago Zannon \\ Soares Nogueira ${ }^{1}$, Ana Beatriz Calmon Nogueira da Gama Pereira ${ }^{2}$.
}

\begin{abstract}
Resumo
A Migrânea é um dos tipos de cefaleia primária, cuja etiologia é multifatorial, acometendo cerca de $15 \%$ da população mundial. Predomina mais nas mulheres do que nos homens, e causa grande impacto na qualidade de vida. São quatro as fases da migrânea: prodrômica, aura, cefaleia propriamente dita e recuperação. Nesse trabalho, os autores buscam correlacionar o efeito da migrânea sobre a qualidade de vida, através de revisão da literatura atual.
\end{abstract}

Como citar esse artigo. Souza, NE, Calumby ML, Afonso EO, Nogueira TZS, Pereira ABCNG. Cefaleia: migrânea e qualidade de vida. Revista de Saúde. 2015 Jul./Dez.; 06 (2): 23-26.

Palavras-chave: Cefaleia. Migrânea. Qualidade de vida. Neurologia.

\begin{abstract}
The migraine is a type of primary headache, whose etiology is multifactorial, affecting about $15 \%$ of world population. More predominant in women than in men and causes great impact on quality of life. There are four phases of migraine: prodromal, aura, headache and recovery. In this work, the authors seek to correlate how migraine affects quality of life, through a review of current literature.

Keywords: Headache. Migraine. Quality of life. Neurology.
\end{abstract}

\section{Introdução}

A dor crônica é, atualmente, um problema de saúde pública que vem acarretando diversos prejuízos, tanto pessoais quanto sociais. Estudos epidemiológicos sobre a dor crônica no Brasil e no restante do mundo são poucos, principalmente quando se trata de dores não específicas. A cefaleia é um exemplo de dor crônica que interfere substancialmente na qualidade vida, sendo umas das causas mais importantes de perda de dias no trabalho e custos dos serviços de saúde. Mais de 120 milhões de americanos sofrem de crises de enxaqueca, cuja intensidade varia de moderada a severa, consecutivamente diminuindo a qualidade de vida e capacidade de trabalho. ${ }^{1}$

A cefaleia é uma condição prevalente, incapacitante, muitas vezes sem diagnóstico e tratamento adequados. Ela afeta mais as mulheres e tem maior frequência nos anos de maior produtividade. No Brasil, as cefaleias são responsáveis por cerca de $9 \%$ das consultas em atenção primária. Estima-se que apenas $56 \%$ dos pacientes com migrânea procuram atendimento de médico generalista e, destes, $4 \%$ e
$16 \%$, respectivamente, consultam com especialistas em cefaleias, sendo mais comum as mulheres buscarem assistência médica por esse motivo. ${ }^{2}$

Segundo a Sociedade Internacional de Cefaleia, a migrânea é classificada como uma cefaleia primária. Caracteriza-se clinicamente por crises intermitentes, dor pulsátil, de moderada a intensa, frequentemente unilateral e com sintomas associados, tais como náuseas e fobias, podendo durar até 72 horas quando não devidamente tratadas. ${ }^{3}$

Nas crianças, a cefaleia é um sintoma que frequentemente leva a preocupação do médico e da família, pois é uma queixa comum tanto na infância quanto na adolescência. A prevalência da cefaleia na infância aumenta numa relação diretamente proporcional à idade das crianças. ${ }^{4}$

Estudos apontam que $60 \%$ a $80 \%$ dos casos de enxaqueca são de natureza genética, ${ }^{5}$ demonstrando assim a importância do pensamento diagnóstico por parte dos clínicos, a fim de proporcionar melhor qualidade de vida aos pacientes.

Sendo assim, observa-se que a melhora da qualidade de vida se deve ao tratamento profilático das migrâneas, que inclui o tratamento medicamentoso

1. Acadêmicos da Universidade Severino Sombra, Curso de Medicina, Vassouras-RJ, Brasil.

2. Professora da Universidade Severino Sombra, Curso de Medicina, Vassouras-RJ, Brasil.

3. Universidade Severino Sombra, Pró-reitoria de Ciências Médicas, Discente do Curso de Medicina, Bolsista PIBIC/USS. 
preventivo, uso de medicamentos abortivos - para os momentos de crise -, terapias acessórias ou não medicamentosas e afastamento dos fatores deflagradores. ${ }^{6}$

\section{Objetivo}

Correlacionar o efeito da migrânea sobre a qualidade de vida, através de revisão da literatura atual.

\section{Metodologia}

Revisão bibliográfica através do banco de dados
Scielo e Medline, utilizando os termos: cefaleia, enxaqueca ou migrânea, dor crônica, infância, qualidade de vida, no período de 1990 a 2014, excluindo artigos sobre cefaleias secundárias. Foram selecionados artigos científicos que relataram estudos sobre as cefaleias primárias. Síntese dos dados: foram encontrados 15 artigos científicos, sendo selecionados aqueles que relataram estudos do tipo relato de caso e revisão de literatura.

\section{Revisão bibliográfica}

Quadro 1. Características dos estudos selecionados que analisaram os efeitos da cefaleia tipo migrânea sobre a qualidade de vida.

\begin{tabular}{|c|c|c|c|c|}
\hline Autor e ano & $\begin{array}{l}\text { Objetivos do } \\
\text { estudo }\end{array}$ & $\begin{array}{l}\text { Tipo de } \\
\text { estudo }\end{array}$ & Métodos & Conclusões \\
\hline $\begin{array}{l}\text { Martins LN et al., } \\
2012\end{array}$ & $\begin{array}{l}\text { Relatar um caso de } \\
\text { migrânea com aura, } \\
\text { comparando-o à } \\
\text { literatura atual, } \\
\text { e demonstrar } \\
\text { a importância do } \\
\text { diagnóstico e tratamento } \\
\text { adequados, visto que a } \\
\text { migrânea gera redução } \\
\text { qualidade de vida. }\end{array}$ & $\begin{array}{l}\text { Relato de } \\
\text { caso }\end{array}$ & $\begin{array}{l}\text { Estudo uma paciente do } \\
\text { Hospital Universitário Sul } \\
\text { Fluminense } \\
\text { (RJ), com diagnóstico de } \\
\text { migrânea com aura, utilizando } \\
\text { como instrumento de pesquisa o } \\
\text { Questionário de Cefaleia } \\
\text { [www.procefaleia.com.br } \\
\text { - 25/02/2010] desenvolvido pelo } \\
\text { Instituto de Neurologia Deolindo } \\
\text { Couto (RJ). }\end{array}$ & $\begin{array}{l}\text { A crise migranosa } \\
\text { provoca um impacto } \\
\text { significativo na } \\
\text { economia e no bem- } \\
\text { estar social de inúmeras } \\
\text { pessoas, já que produz } \\
\text { sofrimento tanto durante } \\
\text { as crises quanto nos } \\
\text { períodos intercríticos. }\end{array}$ \\
\hline $\begin{array}{l}\text { Zukerman E,et } \\
\text { al., } 2004\end{array}$ & $\begin{array}{l}\text { Estuda a qualidade de } \\
\text { vida em populações } \\
\text { portadoras de enxaqueca } \\
\text { e cefaleia crônica diária. }\end{array}$ & $\begin{array}{l}\text { Revisão } \\
\text { Bibliográfica }\end{array}$ & $\begin{array}{l}\text { Através da revisão de literatura, } \\
\text { o uso difundido de diversos } \\
\text { instrumentos específicos para } \\
\text { medir o impacto a curto e longo } \\
\text { prazo da qualidade de vida } \\
\text { nos enxaquecosos; tais } \\
\text { como FACT-G, MOS SF36 e o } \\
\text { EORTC. }\end{array}$ & $\begin{array}{l}\text { Sugere espaço para } \\
\text { intervenções altamente } \\
\text { produtivas, de modo } \\
\text { a reduzir custos para } \\
\text { governos ou indivíduos, } \\
\text { além de permitir uma } \\
\text { melhor qualidade de } \\
\text { vida. }\end{array}$ \\
\hline $\begin{array}{l}\text { Kreling MCGD, } \\
\text { Cruz DALM, } \\
\text { Pimenta CAM, } \\
2006\end{array}$ & $\begin{array}{l}\text { Identificar a prevalência } \\
\text { de dor crônica em } \\
\text { adultos trabalhadores; } \\
\text { analisar a prevalência } \\
\text { de dor crônica conforme } \\
\text { o sexo; e analisar a } \\
\text { prevalência de dor } \\
\text { conforme locais do } \\
\text { corpo }\end{array}$ & Pesquisa & $\begin{array}{l}\text { Amostra de } 505 \text { funcionários da } \\
\text { Universidade Estadual de } \\
\text { Londrina (Paraná, Brasil), } \\
\text { considerando-se uma prevalência } \\
\text { esperada de } 50 \% \text {, margem } \\
\text { de erro de } 4 \% \text { na estimativa } \\
\text { e nível de confiança de } 95 \% \text {. } \\
\text { Estabeleceram-se como } \\
\text { significativos os valores de } \\
\text { p }<0,05 . \text { Os dados foram } \\
\text { coletados por entrevista, com } \\
\text { entrevistadores previamente } \\
\text { treinados para este fim. }\end{array}$ & $\begin{array}{l}\text { A prevalência de dor } \\
\text { crônica encontrada foi } \\
\text { de } 61,4 \% \text {, mais mulheres } \\
\text { do que homens relataram } \\
\text { dor crônica ( } \mathrm{p}=0,0001) \text {. } \\
\text { Os locais de dor mais } \\
\text { prevalentes foram cabeça } \\
(26,7 \%) \text {, região lombar } \\
(19,4 \%) \text { e membros } \\
\text { inferiores }(13,3 \%) .\end{array}$ \\
\hline $\begin{array}{l}\text { Gherpelli JLD, } \\
2002\end{array}$ & $\begin{array}{l}\text { Revisão bibliográfica } \\
\text { sobre o tema tratamento } \\
\text { da cefaléia na infância e } \\
\text { adolescência }\end{array}$ & $\begin{array}{l}\text { Revisão de } \\
\text { Literatura }\end{array}$ & $\begin{array}{l}\text { Revisão bibliográfica através } \\
\text { do banco de dados Medline, } \\
\text { utilizando os termos: cefaléia, } \\
\text { enxaqueca ou migrânea, infância } \\
\text { ou adolescência e tratamento, } \\
\text { no período de } 1966 \text { a } 2001 \text {, } \\
\text { excluindo artigos de revisão e } \\
\text { registros de casos. }\end{array}$ & $\begin{array}{l}\text { Pobreza de estudos } \\
\text { controlados sobre o tema } \\
\text { na faixa etária pediátrica, } \\
\text { apesar da importância } \\
\text { que as cefaléias primárias } \\
\text { apresentam na prática } \\
\text { clínica. }\end{array}$ \\
\hline
\end{tabular}


Quadro 1. Continuação..

\begin{tabular}{|c|c|c|c|c|}
\hline Autor e ano & $\begin{array}{l}\text { Objetivos do } \\
\text { estudo }\end{array}$ & $\begin{array}{l}\text { Tipo de } \\
\text { estudo }\end{array}$ & Métodos & Conclusões \\
\hline Mascella V, 2011 & $\begin{array}{l}\text { Comparar níveis de } \\
\text { stress, ansiedade e } \\
\text { depressão em mulheres } \\
\text { com/sem aura com os de } \\
\text { mulheres com Cefaleia } \\
\text { do Tipo } \\
\text { Tensinal episódica. }\end{array}$ & Pesquisa & $\begin{array}{l}\text { Amostra com } 31 \text { mulheres } \\
\text { divididas em } 2 \text { grupos: } 16 \text { com } \\
\text { diagnóstico de Migrânea com/ } \\
\text { sem aura e } \\
15 \text { com diagnóstico de Cefaleia } \\
\text { do tipo Tensional frequente. } \\
\text { Utilizando os instrumentos ISSL, } \\
\text { BAI e BDI. }\end{array}$ & $\begin{array}{l}\text { Prevalência de pacientes } \\
\text { com prejuízo no ambiente } \\
\text { de trabalho devido à } \\
\text { Migrânea }(51,61 \%) \text {, } \\
\text { presença de Stress na } \\
\text { Migrânea }(100 \%) \text {, } \\
\text { ansiedade diária na } \\
\text { Migrânea }(87,50 \%) \text {. }\end{array}$ \\
\hline $\begin{array}{l}\text { Bigal ME, et al, }{ }^{9} \\
2000\end{array}$ & $\begin{array}{l}\text { Avalia a prevalência } \\
\text { de Migrânea entre os } \\
\text { trabalhadores de um } \\
\text { hospital } \\
\text { universitário, } \\
\text { mensurando a } \\
\text { intensidade, interferência } \\
\text { e impacto dela em } \\
\text { algumas atividades } \\
\text { cotidianas. }\end{array}$ & Pesquisa & $\begin{array}{l}\text { Um total de } 1890 \text { funcionários } \\
\text { respondeu a um questionário que } \\
\text { possibilitava o diagnóstico de } \\
\text { Migrânea, segundo a Sociedade } \\
\text { Internacional de Cefaleia (SIC). }\end{array}$ & $\begin{array}{l}31 \text { funcionários } \\
\text { apresentaram Cefaleia } \\
\text { com características do } \\
\text { tipo migranosa, com } \\
\text { amis de } 15 \text { episódios/ } \\
\text { mês }(1,6 \%), 167 \text { homens } \\
(19,8 \%) \text { e } 679 \text { mulheres } \\
(80,2 \%) \text { referiram dor } \\
\text { moderadamente } \\
\text { limitante a severa limitante. }\end{array}$ \\
\hline
\end{tabular}

\section{Discussão}

A Migrânea é um dos tipos de cefaleia primária, cuja etiologia é multifatorial, acometendo cerca de $15 \%$ da população mundial. ${ }^{3}$ A Migrânea sem aura é frequente em, aproximadamente, $90 \%$ dos pacientes. Estudos revelam que a Migrânea ocorre três vezes mais em mulheres do que homens. ${ }^{10} \mathrm{~A}$ incidência aumentada de Migrânea em parentes próximos, como pais, irmãos, avós e tios; apresenta correlação com 50 a $90 \%$ dos casos. ${ }^{11}$

Nos Estados Unidos da América, uma corporação bancária com 92.637 empregados encontrou prevalência de enxaqueca similares as estatísticas da população geral em $7,7 \%$ dos homens e $19,6 \%$ das mulheres. Através desse estudo, estimou-se custos de 21,5 a 24,4 milhões de dólares em relação à cefaleia tipo migranosa, ${ }^{1}$ demonstrando assim os prejuízos econômicos da Migrânea.

Os indivíduos acometidos com Migrânea tem maior incidência de dores no corpo e limitação física, levando a diminuição mais significante que a osteoartrite, diabetes ou Hipertensão arterial sistêmica, ${ }^{9}$ isso acarreta redução da produtividade. Sabendo-se que $67,3 \%$ dos indivíduos com migrânea tem sua produtividade diminuída se comparado com $24,4 \%$ dos indivíduos com cefaleia do tipo Tensional, ${ }^{1}$ observamos a importância do correto diagnóstico e tratamento da Migrânea, afim de melhorar a qualidade de vida e diminuir gastos com os efeitos causados por essa doença.

\section{Considerações finais}

Objetivando a análise dos efeitos da Cefaleia tipo Migranosa sobre a qualidade de vida dos pacientes acometidos, e de igual modo, considerando os altos custos da economia com a mesma, através de medicação, despesas médicas, além da diminuição significativa do rendimento de trabalho, observa-se a importância do diagnóstico correto e suscinto, conscientizando e educando os pacientes em relação à prevalência do sexo, hereditariedade, fatores predisponentes e desencadeantes, visando um novo olhar para a doença, de modo que ela não cause incapacidade, readaptando-o ao ambiente de trabalho.

Um tratamento correto, contínuo e de baixo custo, ou seja acessíveis, são sinônimos de qualidade de vida, não apenas no mercado de trabalho, mas também no ambiente doméstico, diminuindo o estresse, ansiedade e depressão ocasionados pela Migrânea.

\section{Referências}

1 Zukerman E; Guendler VE; Mercante JP et al.Cefaleia e qualidade de vida. Einstein; 2004; 2 (Supl 1): 73-75.

2 Classificação Internacional das Cefaleias - Subcomitê de classificação das cefaleias da Sociedade Internacional da Cefaleia. $2^{\mathrm{a}}$ ed, Editora Alaude, 2006.

3 Martins LN; Oliveira OWB; Dutra LQ; Rezende AQM et al; Migrânea com Aura, Qualidade de Vida e Tratamento: um relato de caso. Rev. de Saúde, 2010; 1(1): 15-24.

4 Gherpelli JLD. Tratamento das cefaleias. Jornal de Pediatria 2002; 78 ( Supl 1): S3-S8. 
5 Adams AC. Neurologia para o Clínico - Diagnóstico e Tratamento; Livraria e Editora Revinter Ltda, Rio de Janeiro, 2004.

6 Medeiros FLM; Medeiros PLM; Silva WFS et al. Tratamento profilático da migrânea. Migrâneas cefaléias, 2008.

7 Kreling MCGD; Cruz DALM; Pimenta CAM. Prevalência de dor crônica em adulto. Rev Bras Enferm 2006; 59 (4): 509-13.

8 Mascella V. Stress, sintomas de ansiedade e depressão na migrânea e cefaleia tensional. Campinas. Tese [Mestrado em Psicologia] - PUC Campinas; 2011.

9 Bigal ME; Fernandes LC; Moraes FA et al. Prevalência e Impacto da Migrânea em Funcionários do Hospital das Clínicas da Faculdade de Medicina de Ribeirão Preto - USP, Ribeirão Preto, Arq Neuropsiquiatr 2000; 58(2-B): 431-436.

10 Stewart WS, Linet MS, Celentano DD. Migraine headaches and panic attacks. Pshychosom Med 1989;51:559-561.

11 Topczewski A. Cefaleia na Infância e Adolescência: como lidar? São Paulo 2002. Casa do Psicólogo Livraria e Editora Ltda 